WORKING PAPER \#619

PRINCETON UNIVERSITY

INDUSTRIAL RELATIONS SECTION

May 2018

Version: May 2, 2018

http://arks.princeton.edu/ark:/88435/dsp01 mp48sg464

\title{
Whom Do Employers Want? \\ The Role of Recent Employment and Unemployment Status and Age*
}

\author{
Henry S. Farber \\ Princeton University \\ Dan Silverman \\ Arizona State University
}

\author{
Chris M. Herbst \\ Arizona State University \\ Till von Wachter \\ University of California Los Angeles
}

\begin{abstract}
We use a résumé audit study to better understand the role of employment and unemployment histories in affecting callbacks to job applications. We focus on how the effect of career history varies by age, partly in an attempt to reconcile disparate findings in prior studies. While we cannot reconcile earlier findings on the effect of unemployment duration, the findings solidify an emerging consensus on the role of age and employment on callback. First, among applicants across a broad age range, we find that applicants with 52 weeks of unemployment have a lower callback rate than do applicants with shorter unemployment spells. However, regardless of an applicant's age, there is no relationship between spell length and callback among applicants with shorter spells. Second, we find a hump-shaped relationship between age and callback, with both younger and older applicants having a lower probability of callback relative to prime-aged applicants. Finally, we find that those applicants who are employed at the time of application have a lower callback rate than do unemployed applicants, regardless of whether the interim job is of lower or comparable quality relative to the applied-for job. This may reflect a perception among employers that it is harder or more expensive to attract an applicant who is currently employed.
\end{abstract}

*Farber: farber@princeton.edu; Herbst: Chris.Herbst@asu.edu; Silverman: dsilver3@asu.edu; von Wachter: tvwachter@econ.ucla.edu. We thank Jeong Joo Ahn, Nicole Gandre, Zoram Kaul, Elizabeth Kuttner, Tanairi Ochoa-Martinez, and Jason Shumberger for their first-rate work in fielding the study and preparing the data. We thank participants in a workshop at Brigham Young University for helpful comments. Financial support for this project was provided by the Industrial Relations Section at Princeton University. Earlier work on this project formed the basis of Farber's Presidential Address to the Society of Labor Economists, Seattle WA, May 6, 2016. 


\section{Introduction}

The Great Recession led to a dramatic rise both in the unemployment rate and in durations of unemployment. Over the subsequent seven plus years of economic expansion, the unemployment rate has declined sharply but the long-term unemployment rate and the share of long-term unemployment among the unemployed remain at unusually high levels. ${ }^{1}$ Moreover, there was a sharp decline in the labor force participation rate and in the employment-population ratio during the Great Recession, with little recovery since. ${ }^{2}$ These patterns point to the continued difficulty job losers have in finding a job. Along with the difficulty the unemployed have in finding a new job, the quality of job matches formed in recessions tends to be lower (e.g., Bowlus 1995, Farber 1999), and job losers often need to pass through a long series of job moves towards higher-paying jobs (e.g., Stevens 1997, von Wachter, Manchester, and Song 2009). Finally, there is mounting evidence that this job search and matching process is particularly challenging for those just entering the labor market (e.g., Kahn 2010, Schwandt and von Wachter 2017) and for older workers who are unlucky enough to lose a job in a recession (e.g., Chan and Stevens 2001, Farber 2017).

The elevated long-term unemployment rate, the substantial fraction of unemployment that is long term, and the protracted job instability and low job quality that job losers experience reinforce the importance of understanding the determinants of successful job search. In particular, given the job losses associated with a major recession, it is important to understand better the roles played by specific features of employment history in determining the employment process.

To better understand the determinants of job search outcomes, our work uses an audit study approach. The approach introduces random variation in the characteristics of fictitious résumés sent to job applications, and examines the effects of these characteristics on callback

\footnotetext{
${ }^{1}$ The long-term unemployment rate has fallen substantially since its peak of 4.2 percent in 2010 , but it remains (at about 1.1 percent in 2017) above its rate in earlier strong labor markets. Perhaps more striking, the long-term share of unemployment, which peaked at 44 percent in 2011, remains very high by historical standards at 24 percent in 2017. The long-term share of unemployment was 18 percent in 2007, prior to the Great Recession. These statistics are based on the authors' calculations using data from the Current Population Survey.

${ }^{2}$ The labor force participation rate fell from 66 percent in 2007 to 64 percent in 2012 and fell further to 63 percent in 2017. Over the same period, the employment-population ratio fell from 63 percent in 2007 to 59 percent in 2011 before recovering slightly to 60 percent in 2017. These statistics are based on the authors' calculations using data from the Current Population Survey.
} 
rates. ${ }^{3}$ Recent audit studies have focused on unemployment duration, the role of age, and, to a lesser degree, on the presence and quality of a current (often interim) job. We provide an integrated assessment of the effect of unemployment duration, age, and interim job status on callbacks by randomly varying applicant characteristics in these dimensions on résumés submitted in response to a large number of job postings.

In doing so, the current study seeks to reconcile contrasting results in the existing literature (reviewed below) and to integrate results on age and recent employment history. Although our earlier work (Farber, et al., 2016; 2017) is methodologically similar to Kroft, et al., (2013), they find a strong negative relationship between the callback rate and unemployment duration while we find no such relationship. In Farber et al. (2017), we attempt a detailed reconciliation with Kroft, et al. (2013), focusing on potential differences between the two analyses with respect to the measure of callback, type of job, applicant education, applicant age, and the particular cities included. Age was the the primary dimension that we could not rule out as the source of the different findings because of a lack of overlap in age between the two studies. ${ }^{4}$ Hence, an important goal for this study is to return to the field with a design that varies unemployment durations and includes applicants covering a broad range of ages.

In pursuit of both an integrated assessment of several obstacles to job search after job loss, and important missing pieces in the literature, we fielded an audit study in 2017 varying treatments of unemployment duration, age, and the current employment status of the applicant. We kept all other aspects of the résumés as similar as possible to those in our earlier work. We visited the same eight cities with female applicants of similar education (college graduates) applying for the same type of jobs (white collar office jobs such as administrative or executive assistants, receptionists, secretaries, and the like). Of course we could not hold fixed the state of the labor market. The labor markets in our cities are uniformly stronger in 2017 than they were when we fielded our earlier experiment (2012-2014).

We obtain several key findings. First, our results for the currently employed are clear. Average callback rates are significantly lower for those applicants with an interim job, re-

\footnotetext{
${ }^{3}$ An important early example of an audit study in labor economics is Bertrand and Mullainathan (2004), who study the effect of African-American sounding names on callback rates. Jarosch and Pilossoph (2016) present a clear analysis illustrating the limitations of résumé audit studies in measuring variation in hiring that highlights the distinction between a callback and the eventual hiring decision.

${ }^{4}$ Kroft, et al. (2013) analysis focused on young applicants, aged 21-33, while Farber, et al., (2016, 2017) focused on older applicants, aged 35-58.
} 
gardless of the quality than for those who are unemployed. The unemployed had an average callback rate of 12.6 percent, while the rate was 10.8 percent and 10.2 percent for those holding a high and low quality interim job, respectively. Interestingly, this negative effect of holding an interim job obtains only when applying to a relatively high-skilled position. Callbacks for clerical, data entry, office assistant, and other lower-skilled positions are not higher for the unemployed. Those without a job receive callbacks at a higher rate only for administrative or executive assistant, office manager, or other relatively high skilled positions, which also tend to have higher education requirements. These results suggest that the path back to career work may be more challenging for many workers than is typically understood because, perhaps surprisingly, on-the-job search can be significantly less fruitful when employed than when searching from unemployment.

Second, there are substantial effects of age, but these cut two ways; both the youngest (age 22-23) and the oldest (age 60-61) applicants have significantly lower callback rates than do prime-age applicants. Hence, we confirm the negative effects for older workers reported in other audit studies. The negative effects for younger workers is partly accounted for by the fact that very young job applicants often have less relevant work experience than recommended or required for the job. Any remaining deficit for younger workers dovetails with a longstanding literature on adverse consequences of early employment shocks.

Third, we find a limited effect of unemployment duration on the likelihood of callbacks. There are no distinctions in callback rates among applicants with unemployment durations of 24 weeks or less, but applicants who have been unemployed for a year have a lower callback rate. The callback rate was 11.6 percent for applicants with 24 weeks of unemployment, while applicants with 52 weeks of unemployment had a callback rate of 9.1 percent. This finding adds further complexity to the already contrasting findings on unemployment duration dependence from prior audit studies.

Finally, we find little evidence of differences in the effect of unemployment duration by age. Hence, there is little reason to think that differences in the ages of the applicants can explain the differences in results across previous studies. We find average callback rates are, for all age categories, at their lowest after a year of unemployment.

One broad conclusion is that, while résumé audit studies may be useful in shedding light on the process of job search and hiring, not enough is known how, why, and when employers respond to résumé characteristics when making their callback decisions. Clearly, employers respond to features of the résumé in their callback decision in a way that can be replicated 
across studies, such as age or current employment status. However, it unclear why this is not true for unemployment duration. These uncertainties suggest additional caution in interpreting the results from audit studies and limits to their external validity, especially in the case of the relationship between callbacks and unemployment duration.

\subsection{Related Audit Study Literature}

An increasing number of studies implement résumé audit studies to assess the impact of resume characteristics on the likelihood of callback. One especially relevant subset of the literature focuses on the effect of the duration of an applicant's unemployment spell on callback rates. These studies have obtained mixed results. Some find a negative effect of unemployment duration on the probability of callback concentrated in the first six months of the unemployment spell (Kroft et al., 2013; Ghayad, 2014). In contrast, Nunley et al. (2017) and Farber et al. (2016; 2017) find no effect of unemployment duration on callback rates in U.S. markets. Focusing on Sweden, Eriksson and Rooth (2014) find no effect for highly educated workers and a negative effect for spells lasting more than 6 months for low educated workers. One difficulty in comparing and assessing the different outcomes of these studies is that they focus on workers of different ages and levels of education. Kroft et al., (2013) and Ghayad (2014) focus on younger workers for a range of education groups, Nunley et al. (2017) focus on younger college graduates, and Farber et al. (2016; 2017) focus on older college graduates.

Motivated by the difficulties unemployed older workers face in the labor market, another group of audit studies addresses how applicant age affects callback rates. The results generally show a negative relationship between age and callbacks for older and middle-aged workers. Lahey (2008) finds large negative effects of age on callbacks for women seeking entry-level positions in the U.S. Neumark et al. (2015; 2016), in a large scale audit study, find significantly lower callback rates for older women but weaker evidence for men in several occupations. Bendick, et al. (1997) find evidence that both older men and older women had lower callback rates than their younger counterparts. Farber, et.al. (2016; 2017) find that older females have lower callback rates than middle-aged females. So far, no study has compared callback rates by age for younger vs. middle aged vs. older workers. This open question, which we address here, takes on greater importance given the increasing evidence that younger workers are particularly hurt by adverse labor market conditions as well (e.g., Kahn 2010, Oreopoulos, et al. 2012, Schwandt and von Wachter 2017). 
Last, a smaller number of studies assess the effect of holding a job at the time of application on the probability of a callback. Farber, et al. $(2016 ; 2017)$ find that workers who are currently employed in an interim job at a lower level than the one for which they are applying have a lower callback rate than those who are unemployed. This finding is similar to that in Nunley et al. (2017), who found that recent college graduates in the U.S. had substantially lower callbacks if they were currently employed in jobs that did not require a college education and were not suited to the job for which they were applying. A related but distinct finding of Kroft, et al. (2013) is that individuals who are currently employed in a job similar to the one for which they are applying are significantly less likely to receive a callback. These findings are consistent with the idea that employers believe employed job seekers are more difficult to hire because they are likely to have a higher reservation wage and be more expensive to recruit. An open question that we address here is whether the job type at which workers are employed matters, or whether employment, per se, lowers callback rates.

\section{A Simple Theoretical Framework}

To guide interpretation of the experimental design and results, we offer a simple theory of employer learning about worker quality from resume characteristics. A straightforward implication of the theory is that employers, when evaluating older applicants, will place less weight on the duration of a recent unemployment spell because there is more information available about their labor market performance through previous experience. ${ }^{5}$

We assume a profit-maximizing, risk-neutral firm with a single worker. The output $(Y)$ of the firm is equal to the quality of the worker $(\mu)$. We assume all hired workers will be paid the same wage so that the firm is interested in the most able worker among applicants for its opening. The model captures the employer's process of integrating available information to form an expectation of applicant quality. While we do not develop a formal sequential search model, the standard model has the property that the employer will set a reservation worker quality level $\left(\mu^{*}\right)$ as part of the search process and call back those applicants whose expected quality exceeds this threshold $\left.\left(E\left(\mu_{i}\right)>\mu^{*}\right)\right)$, so that applicants with higher expected quality will be more likely to receive a callback.

\footnotetext{
${ }^{5}$ A more detailed presentation of this model is available in Farber, et al. (2017).
} 
Consider applicant $i$. The firm has incomplete information about $\mu_{i}$ and makes an inference based on a set of $k$ noisy signals. For the purposes of our study, these signals include, among other background information, the applicant's employment experience, age, and whether the applicant holds an interim job of a given type. Let $s_{i j}$ represent the $j^{\text {th }}$ noisy signal of $\mu_{i}$. We assume this $j^{\text {th }}$ signal satisfies

$$
s_{i j}=\frac{1}{\alpha_{j}} \mu_{i}+\gamma_{i j}
$$

where $\gamma_{i j}$ is a normally distributed random variable with zero mean and variance $\sigma_{j}^{2}$. The parameters $\alpha_{j}$ are normalizations that account for the fact that some signals are positive and some are negative as well as for differential scaling of the signals. For example, unemployment duration would have $\alpha_{j}<0$, but a high-quality interim job might have $\alpha_{j}>0$. The employer's inference problem is to combine the available information on $s_{i j}, j=1, \ldots, k$ optimally in order to derive an expected value for applicant quality $\left(E\left(\mu_{i} \mid s_{i 1}, \ldots, s_{i k}\right)\right)$.

Posterior beliefs about applicant quality can be derived using a standard Bayesian procedure. Given the distributional assumption regarding the $\gamma_{i j}$, each signal $s_{i j}$ about applicant quality is normally distributed with mean $\mu_{i} / \alpha_{j}$ and variance $\sigma_{j}^{2}$. To describe how information about $s_{i j}$ is combined to form the employer's posterior distribution on applicant quality, it is convenient to use the precisions of the random variables rather than the variances. The precision $(h)$ of a random variable is the inverse of the variance, so that $s_{i j}$ with variance $\sigma_{j}^{2}$ has precision $h_{j} \equiv 1 / \sigma_{j}^{2}$. In this Normal Bayesian updating model, the posterior distribution of the employer's beliefs about $\mu_{i}$ is normal with a mean that is a precision-weighted average of the $k$ signals. The posterior expectation is

$$
E\left(\mu_{i} \mid s_{i 1}, \ldots, s_{i k}\right)=\frac{\sum_{j=1}^{k} h_{j} \alpha_{j} s_{i j}}{\sum_{j=1}^{k} h_{j}} .
$$

The model has a clear implication for the effect of any particular factor (signal $\mathrm{m}$ ) on the likelihood of a callback. The marginal effect of a change in $s_{i m}$ is

$$
\frac{\partial E\left(\mu_{i}\right)}{\partial s_{i m}}=\alpha_{m}\left[\frac{h_{m}}{\sum_{j=1}^{k} h_{j}}\right]
$$

which takes the sign of $\alpha_{m}$. If, for example, signal $m$ is unemployment duration then, presumably, $\alpha_{m} \leq 0$, and the marginal effect of unemployment duration is negative. Thus, workers with longer unemployment duration have lower posterior mean worker quality. This makes their posterior expected quality less likely to exceed the necessary threshold $\left(\mu^{*}\right)$, which implies a lower likelihood of callback. 
We found in our earlier work that holding a low-quality interim job reduced the likelihood of receiving a callback, but we do not have a strong prior on the effect of holding interim jobs of differing quality on the likelihood of a callback. On the one hand, holding an interim job of any quality could indicate that the applicant is energetic and ambitious. On the other hand, the holding of a low-level interim job could indicate to the employer (particularly on a cursory reading of the résumé) that the worker is ill-suited for the job. Additionally, the employer might feel that currently-employed applicants, regardless of job quality, are more difficult or expensive to recruit. This implies ambiguity about the sign of $\alpha_{m}$ associated with the holding of an interim job of a given type.

In our discussion of the existing literature, we highlighted the potential for age to explain the mixed results on the relationship between unemployment duration and callback rates.

Prior analyses that find duration dependence in callbacks, especially Kroft, et al. (2013), focused on younger applicants. Indeed, there are good theoretical reasons that unemployment duration would be more important for young workers.

The key prediction of the model for understanding how the relationship between unemployment duration and the likelihood of callback is mediated by age is that when there are more signals of worker quality, the marginal effect of any one signal will be smaller in absolute value. An older worker has more prior work experience and, as a result, more signals of worker quality. This comes in the form of more and perhaps longer-lasting prior jobs. In the context of the model, longer experience and more information increase the number of signals $(k)$. The marginal effect of a particular signal is given in equation 3 . On inspection of this relationship, an increase in $k$ increases the denominator in the term in brackets (an increase in the precision of the prior belief regarding $\mu$ ). The result is a reduction in the absolute value of the marginal effect of any particular signal.

Thus, the model predicts that the marginal effect of unemployment duration on the likelihood of receiving a callback will be smaller for older workers. Our current analysis, which covers the full age spectrum allows us to investigate whether any relationship between unemployment duration the callback rate varies systematically with age.

\section{Research Design}

The design of our study closely follows, and then extends, the design in Farber et al. (2017). As with prior correspondence audit studies, the design randomly assigned several job-seeker 
Table 1: Unemployment Rates, by City and Year

\begin{tabular}{lrrr|lrrr} 
Low Unemployment & 2012 & 2014 & 2017 & High Unemployment & 2012 & 2014 & 2017 \\
\hline Dallas, TX & 6.6 & 5.0 & 3.9 & Charlotte, NC & 9.2 & 6.0 & 4.2 \\
Omaha, NE & 4.4 & 3.7 & 2.9 & Chicago, IL & 9.1 & 7.0 & 5.3 \\
Pittsburgh, PA & 7.2 & 5.6 & 5.2 & Sacramento, CA & 10.3 & 7.2 & 5.2 \\
Portland, ME & 6.1 & 4.6 & 2.5 & Tampa, FL & 8.3 & 6.1 & 4.0 \\
\hline Average & 6.1 & 4.7 & 3.7 & Average & 9.2 & 6.6 & 4.7
\end{tabular}

characteristics to résumés submitted on behalf of fictitious individuals in response to real job advertisements. We then recorded whether each résumé received a positive response. The setting for the experiment consists of two large on-line job boards in the U.S. We used these websites to search for jobs in 8 cities: Charlotte, Chicago, Dallas, Omaha, Pittsburgh, Portland (ME), Sacramento, and Tampa. These cities were originally selected by Farber et al. (2017) to allow for treatment effect differences by local-area unemployment rates. Therefore, half of the cities studied had relatively low unemployment rates in 2012 (Dallas, Omaha, Pittsburgh, and Portland) while the other half had relatively high unemployment rates in 2012 (Charlotte, Chicago, Sacramento, and Tampa).

Table 1 presents city-level unemployment rates for the 8 cities in 2012 (early in the Farber, et al. (2017) study period) and 2014 (late in the Farber, et al. (2017) study period), and in 2017 (the period covered in this study). The table illustrates the improvement in the labor market during the extended recovery from the Great Recession. Unemployment rates have fallen sharply in both the low- and the high-unemployment cities, and the relative ordering of cities by unemployment rate was largely preserved across the groups. Given the general strengthening of labor markets over the past 7 years, the distinction between the low- and high-unemployment cities is less salient than it was at the time we designed our previous study, and we will not evaluate the low-high unemployment distinction in the present analysis.

To reduce idiosyncratic variation in interview requests, we made design choices aimed at ensuring that the résumés and job openings were well-matched. Applications were limited to white collar office positions, including administrative or executive assistants, receptionists, secretaries, and office associates. Our procedure for finding positions to which résumés would be submitted entailed searching for particular keywords in the position description. ${ }^{6}$

\footnotetext{
${ }^{6}$ These terms included Administrative Assistant (90.5 percent), Receptionist (6 percent), Office Assistant
} 
Table 2: Characteristics of Posted Jobs

\begin{tabular}{llr||lr} 
Job Category & Skill & Percent & Education Category & Percent \\
\hline Receptionist & Low & 22.2 & High School Degree & 28.3 \\
Office Assistant & Low & 6.6 & Associates Degree & 8.6 \\
Clerical / Data Entry & Low & 4.3 & Bachelors Degree & 11.1 \\
Other - Low Skill & Low & 1.0 & Not Available & 52.0 \\
\hline Administrative Assistant & High & 52.6 & & \\
Executive Assistant & High & 6.4 & & \\
Office Manager & High & 4.5 & & \\
Other - High Skill & High & 2.3 & &
\end{tabular}

Note: Job Category is a classification based on the posted job title. Skill classification is subjective. Education Category indicates the highest education level recommended or required for posted position.

Importantly, there were more than 1,200 different job titles associated with the jobs openings to which we applied. We then did a textual analysis of the job titles associated with the selected positions in our sample and subjectively assigned the job titles to the 8 categories listed in the left panel of Table 2. Most jobs fall in the 2 categories Administrative Assistant and Receptionist. We further collapse these 8 job categories into 2 groups: 1) "low skill" (Receptionist, Office Assistant, Clerical / Data Entry, and Other - Low), comprising 34.1 percent of postings, and 2) "high skill" (Administrative Assistant, Executive Assistant, Office Manager, and Other - High), comprising 65.9 percent of postings. We will utilize this lowhigh skill distinction in our analysis.

Given that these jobs are disproportionately held by women, all applicants are assigned female names. Each applicant has a four-year bachelor degree from a non-elite public university or college whose admission rate exceeds 65 percent. The distribution of required or recommended educational attainment in the job postings is listed in the right column of Table 2. Fully 52 percent of postings do not list an education level. A high school degree is specified in 28.3 percent of postings, an associate's degree in 8.6 percent, and a bachelor's degree in 11.1 percent. The posted education level is correlated with the skill level of the job category as we define it. ${ }^{7}$ Among postings specifying a bachelors degree, 84.4 percent are high skill. Among postings specifying an associates degree, 79.4 percent are high skill. The fraction high-skill falls to 62.6 percent among postings specifying a high school degree. The

(2.3 percent), and Executive Assistant (1 percent).

${ }^{7}$ Education level was not used to assign skill category. 
fraction high-skill is 61.5 percent among postings with no specified education level, suggesting that these postings are more likely to be open to applicants with less education. Given that all our applicants have a four-year bachelor's degree, they may be over-qualified for some of the low-skilled job postings. For this reason, we present some analyses making a distinction between the postings we classify as low-skill and those we classify as high skill.

Many of our applicants have substantial work histories, which are perforce longer for older applicants. The work histories generally consist of three to six white collar jobs. Prior to the current unemployment spell, these work histories had no employment gaps longer than a month in the previous five years. Age and birth year are not listed on the résumés but are instead inferred from information on year of college completion and work experience.

The fictitious résumés were modeled on real résumés posted publicly on a website that was not used for the purposes of data collection for this study. These "source" résumés were used by individuals to apply for positions similar to the target occupations we study but were in cities that were not included in the study. We migrated the characteristics of these source résumés to our fictitious résumés, modified suitably so that, city-by-city, the residential addresses, employers, and post-secondary education institutions are geographically appropriate. We did not migrate the names listed on the source résumés, but instead selected common, cohort-specific names from lists maintained by the Social Security Administration. These résumé names are racially and ethnically neutral in that they are not held disproportionately by a particular racial or ethnic group. ${ }^{8}$

Fieldwork began in March 2017 and ended in August 2017. A group of research assistants regularly searched both websites for job advertisements that had been posted within the past 7 days and that were located within a 25-mile radius of a given city. The 7 -day criterion increased the odds that our résumés were evaluated by employers, while the 25-mile radius ensured that the pool of openings included a sufficiently large number of jobs. We sent 4 résumés in response to each job advertisement. Each résumé was accompanied by a cover letter that provided a broad summary of the applicant's credentials listed on the résumé. ${ }^{9}$ On one of the job websites résumés were submitted directly to employers via email addresses provided by the website host. Résumés on the other website were forwarded to

\footnotetext{
8 The names used in this study were Susan Taylor, Lauren Daniels, Donna Ramsey, Rose Peters, Angela Nelson, Heather Adams, Jennifer Smith, Shannon Robinson, Janice Evans, Linda Carter, Mary Wilcox, and Joan Mason.

9 The appendix includes a sample of three cover letters and their associated résumés.
} 
employers through the job board's on-line submission portal. To minimize suspicion that the four résumés were "connected," we let several hours elapse between each submission. The research assistants collected information about each job advertisement and firm, including the job title, name and location of the firm, contact information, industry code, and any experience or education requirements. Altogether our analysis data-set includes 8,488 résumés submitted in response to 2,122 job advertisements. ${ }^{10}$

The essence of the experiment was to manipulate three variables: length of contemporaneous unemployment spell, presence and nature of contemporaneous "interim jobs," and age of applicant. Regarding the first source experimental variation, the work histories were designed such that a base set of résumés indicated that the applicant was just entering unemployment at the time of résumé submission, while other résumés indicated a specific number of weeks of unemployment from the set $\{4,12,24,52\}$. The start of the unemployment spell was indicated on the résumé by the end date of the applicant's most recently held job. Therefore, those in the base group listed on her résumé that her most recent job had ended in the month immediately preceding the month in which the application was submitted. The unemployment spells were drawn with replacement from the set $\{0,4,12,24,52\}$ and were intended to be assigned with equal probability. There was, however, a glitch in the implementation of the sampling during May, June, and July 2017, and the probabilities were not equal for applications during that period. ${ }^{11}$

The second source of experimental variation assigned applicants to one of three interimjob categories: a low-skilled interim job, a high-skilled interim job, and no interim job. The low-skilled interim job was shown to begin the month in which a given résumé was submitted (following whatever length unemployment spell was assigned to that résumé), and included employment at a chain restaurant, a big box retail store, or a grocery store. These jobs generally involved serving food, stocking shelves, or assisting customers at a register or on a retail floor. Thus this job experience was designed to appear quite different from the career work outlined on the rest of the résumé and is generally of lower skill and responsibility than

\footnotetext{
10 The complete data set contains 8,899 résumés submitted in response to 2,304 job postings. A small number of job postings (182) inadvertently received less than four submissions and we delete all the submissions to these 182 postings from our analysis. None of our results are affected by omitting the 411 completed submissions to these 182 postings.

${ }^{11}$ During these three months, most of the resumes that should have had a 24 week unemployment duration actually had a zero unemployment duration. The actual fractions with each unemployment treatment ranged, over the entire period, from 0.128 with 24 weeks duration to 0.279 with 0 weeks duration. The other three durations $(4,12$, and 52 weeks) had fractions very close to 0.20 .
} 
the posted jobs. The high-skilled interim jobs also began in the month of résumé submission (following whatever length unemployment spell was assigned to that résumé). However, this category included jobs in industries and occupations that matched applicants' broader work history. While the responsibilities on these interim jobs were somewhat downgraded relative to the responsibilities listed for the most recently held job, these were more comparable to the posted jobs and particularly to the lower-skill posted jobs as described above. The third group of résumés did not list an interim job so that these applicants appeared to be currently unemployed along with some unemployment duration as described above. These three treatments were assigned with replacement and with equal probability.

The third source of experimental variation assigned each applicant an age from the set \{22-23, 27-28, 33-34, 42-43, 51-52, 60-61\}. Although age was not stated on the résumés, it could be inferred by employers from the college graduation dates as well as the start (and end) dates of the jobs listed throughout the employment history. At the beginning of every month we adjusted the employment dates accordingly so that our fictitious applicant did not "age" throughout the study. Age categories were assigned without replacement within a job posting and with equal probability.

The experiment was designed so each dimension of variation (unemployment duration, interim job, and age) was assigned independently. This facilitates the examination of interactions across these dimensions. For example, there might be a differential impact of unemployment duration or interim job by age.

To enable communication between employers and our fictitious applicants, we created a telephone number for each city-name combination in the study, for a total of 96 numbers (8 cities * 12 names). An email address was also established for our applicants according to the same rules. The research assistants regularly monitored these accounts and recorded whether résumés received a message from an employer. In particular, they coded three categories of responses: interview requests, a request for more information, and rejections. An interview request is defined as the receipt of either an explicit interview request or an invitation to discuss the résumé and/or position in more detail. A request for more information was coded if the applicant was asked to fill out an application, answer clarifying questions, provide additional information, or interview for a different position. A rejection was coded if the applicant received a message from the employer saying that the résumé was not selected to move to the next round of the hiring/interview process. Résumés that received no correspondence from an employer were ultimately coded as a rejection. Potential employers 
who did respond were promptly informed that the applicant was no longer available.

\section{Results}

We begin by analyzing the effect of unemployment duration and age on the likelihood of a callback. In an attempt to reconcile our earlier findings (Farber, et al, 2016, 2017) with findings of Kroft, et al. (2013), we then investigate how the relationship between unemployment duration and the likelihood of callback varies with age. Next, we consider how the presence of an interim job affects the likelihood of callback. Finally, we consider the extent to which holding an interim job of different types (low skill vs. high skill) has differential effects on callback rates and how these effects are related to the skill level of the applied-for job (also low skill vs. high skill).

We provide three measures of what constitutes a callback: 1) any callback, 2) a callback asking for more information, and 3) a callback requesting an interview. Overall, the anycallback rate is 11.2 percent, the information-callback rate is 3.0 percent, and the interviewcallback rate is 8.2 percent. One plausibility check that our resumes work as intended is that the any-callback rate was significantly $(p$-value $<0.0005)$ higher in our low-unemployment cities (at 12.6 percent) than in our high-unemployment cities (at 10.1 percent). The same relationship holds considering information callbacks and interview callbacks separately. In what follows, we present some first-order results that consider different types of callbacks separately, but we largely emphasize any-callbacks.

\subsection{Duration of Unemployment}

A primary focus of this study is to examine the effect of unemployment duration on the likelihood of receiving callback to a job application. Table 3 contains mean callback rates for each of the three callback measures and each of the five values for unemployment duration. The table also contains the results of Pearson $\chi^{2}$ tests of the independence of callbacks and unemployment duration. Independence can be rejected for any-callback and for each category of, callback, but there is not a progressive relationship between callbacks and unemployment duration. The callback rate is lower for those with the highest unemployment duration (52 weeks) than for those with shorter unemployment spells, but there does not seem to be a distinction in callback rates for those with unemployment spells between 0 and 24 weeks.

Pearson $\chi^{2}$ tests of independence of each measure callback and unemployment duration 
Table 3: Average Callback Rate, by Unemployment Duration

\begin{tabular}{|c|c|c|c|c|}
\hline Weeks U & N Apps & $\begin{array}{c}(1) \\
\text { Callback } \\
(\text { Any })\end{array}$ & $\begin{array}{c}(2) \\
\text { Callback } \\
\text { (Information) }\end{array}$ & $\begin{array}{c}(3) \\
\text { Callback } \\
\text { (Interview) }\end{array}$ \\
\hline 0 & 2370 & $\begin{array}{c}0.110 \\
(0.007)\end{array}$ & $\begin{array}{c}0.034 \\
(0.005)\end{array}$ & $\begin{array}{c}0.076 \\
(0.006)\end{array}$ \\
\hline 4 & 1768 & $\begin{array}{c}0.118 \\
(0.008)\end{array}$ & $\begin{array}{c}0.036 \\
(0.005)\end{array}$ & $\begin{array}{c}0.081 \\
(0.007)\end{array}$ \\
\hline 12 & 1632 & $\begin{array}{c}0.123 \\
(0.009)\end{array}$ & $\begin{array}{c}0.026 \\
(0.004)\end{array}$ & $\begin{array}{r}0.097 \\
(0.008)\end{array}$ \\
\hline 24 & 1083 & $\begin{array}{c}0.119 \\
(0.011)\end{array}$ & $\begin{array}{c}0.029 \\
(0.006)\end{array}$ & $\begin{array}{c}0.090 \\
(0.010)\end{array}$ \\
\hline 52 & 1635 & $\begin{array}{c}0.091 \\
(0.008)\end{array}$ & $\begin{array}{c}0.021 \\
(0.004)\end{array}$ & $\begin{array}{c}0.070 \\
(0.007)\end{array}$ \\
\hline All & 8488 & $\begin{array}{c}0.112 \\
(0.005)\end{array}$ & $\begin{array}{c}0.030 \\
(0.003)\end{array}$ & $\begin{array}{c}0.082 \\
(0.004)\end{array}$ \\
\hline $\begin{array}{c}\text { Pearson } \chi^{2} \\
p \text {-value }\end{array}$ & & $\begin{array}{l}10.5 \\
0.033\end{array}$ & $\begin{array}{l}8.7 \\
0.068\end{array}$ & $\begin{array}{c}10.4 \\
0.034\end{array}$ \\
\hline
\end{tabular}

Note: Numbers parentheses are standard errors clustered by job id. The Pearson $\chi^{2}$ and associated $p$-value refer to a test of independence between unemployment duration and the measure of callback. Sample consists of 8,488 applications for 2,122 job postings.

omitting the 52 -week category fails to reject independence (all $p$-values $>0.4$ ). Hence, the overall rejection of independence is entirely driven by the lower callback rates for applicants with 52 weeks of unemployment.

The variation in unemployment duration treatment within job posting in each round offers the opportunity to examine within-posting variation in callback rates by unemployment treatment. The fixed-effect conditional logit analysis due to Chamberlain (1980) is a natural way to estimate this within-posting effect. Intuitively, the fixed-effect conditional logit conditions on the number of successes (callbacks) within each job posting and asks whether the applicants with longer unemployment durations were less likely to be among those who received the fixed number of callbacks. This approach ignores the job postings for which there was no variation in the outcome. Each of our 2122 job postings received 4 applications. 1601 (75.5 percent) postings had no callbacks and 37 postings (1.7 percent) had 4 callbacks. This leaves 246 postings with 1 callback, 161 postings with 2 callbacks, and 77 postings with 3 callbacks. We postpone estimation of the full Chamberlain fixed-effect logit model until Section 4.5 and, for now, present just the average callback rates by unemployment treatment conditional on the number of callbacks received for the job posting. For concision, we present 
Table 4: Average Callback Rate, by Unemployment and Number of Any-Callbacks

\begin{tabular}{c|cccc} 
& $(1)$ & $(2)$ & $(3)$ & $(4)$ \\
Weeks U & 1-3 Callbacks & 1 Callback & 2 Callbacks & 3 Callbacks \\
\hline 0 & 0.422 & 0.274 & 0.500 & 0.789 \\
4 & $(0.019)$ & $(0.021)$ & $(0.029)$ & $(0.040)$ \\
& 0.426 & 0.244 & 0.527 & 0.692 \\
12 & $(0.021)$ & $(0.027)$ & $(0.033)$ & $(0.042)$ \\
& 0.454 & 0.297 & 0.546 & 0.831 \\
24 & $(0.024)$ & $(0.028)$ & $(0.042)$ & $(0.047)$ \\
& 0.429 & 0.261 & 0.494 & 0.795 \\
52 & $(0.030)$ & $(0.036)$ & $(0.047)$ & $(0.057)$ \\
& 0.327 & 0.156 & 0.425 & 0.661 \\
& $(0.024)$ & $(0.026)$ & $(0.041)$ & $(0.050)$ \\
\hline N Postings & 484 & 246 & 161 & 77 \\
Pearson $\chi^{2}$ & 14.3 & 11.9 & 4.2 & 6.9 \\
$p$-value & 0.006 & 0.018 & 0.385 & 0.144
\end{tabular}

Note: The callback rate is 0.25 for postings with 1 callback, 0.5 for postings with 2 callbacks, and 0.75 for postings with 3 callbacks. Standard errors clustered by job id are in parentheses. The Pearson $\chi^{2}$ and associated $p$-value refer to a test of independence between unemployment duration and any-callback.

only analysis of only the any-callback rate, and do not distinguish information requests from requests for interviews.

Table 4 contains these any-callback rates conditional on the number of callbacks received. Column 1 of the table contains average callback rates by unemployment treatment for job postings with 1-3 callbacks. The Pearson $\chi^{2}$ statistic implies rejection of independence of callback and unemployment duration. Again, this is driven entirely by a significantly lower callback rate for applications showing 52 weeks of unemployment and no differences among applications showing shorter unemployment spells. Column 2 shows average callback rates for job postings with 1 callback. These show that same pattern as in column 1, with a significantly lower callback rate for applications showing 52 weeks of unemployment. Columns 3 and 4 of table 4 show the same statistics for job postings with 2 and 3 callbacks respectively. While the general pattern is the same, with a lower callback rate for the highest unemployment category, independence cannot be rejected and there are no significant differences by unemployment duration. The relative imprecision of the within-posting estimates for postings with 2 and 3 callbacks is likely a result of the relatively small sample sizes.

We will revisit the relationship between the callback rate and unemployment duration in more detail later with particular focus on how the relationship varies with age. The 
Table 5: Average Callback Rate, by Age of Applicant

\begin{tabular}{|c|c|c|c|c|}
\hline Age & N Apps & $\begin{array}{c}(1) \\
\text { Callback } \\
\text { (Any) }\end{array}$ & $\begin{array}{c}(2) \\
\text { Callback } \\
\text { (Information) }\end{array}$ & $\begin{array}{c}(3) \\
\text { Callback } \\
\text { (Interview) }\end{array}$ \\
\hline \multirow[t]{2}{*}{$22-23$} & \multirow[t]{2}{*}{1304} & 0.094 & 0.028 & 0.067 \\
\hline & & $(0.009)$ & $(0.005)$ & $(0.007)$ \\
\hline \multirow[t]{2}{*}{$27-28$} & \multirow[t]{2}{*}{1572} & 0.111 & 0.029 & 0.083 \\
\hline & & $(0.008)$ & $(0.004)$ & $(0.007)$ \\
\hline \multirow[t]{2}{*}{$33-34$} & \multirow[t]{2}{*}{1460} & 0.129 & 0.034 & 0.095 \\
\hline & & $(0.009)$ & $(0.005)$ & $(0.008)$ \\
\hline \multirow[t]{2}{*}{$42-43$} & \multirow[t]{2}{*}{1368} & 0.126 & 0.037 & 0.089 \\
\hline & & $(0.009)$ & $(0.005)$ & $(0.008)$ \\
\hline \multirow[t]{2}{*}{$51-52$} & \multirow[t]{2}{*}{1439} & 0.110 & 0.031 & 0.080 \\
\hline & & $(0.009)$ & $(0.005)$ & $(0.008)$ \\
\hline \multirow[t]{2}{*}{$60-61$} & \multirow[t]{2}{*}{1345} & 0.097 & 0.022 & 0.075 \\
\hline & & $(0.008)$ & $(0.004)$ & $(0.008)$ \\
\hline \multirow[t]{2}{*}{ All } & \multirow[t]{2}{*}{8488} & 0.112 & 0.030 & 0.082 \\
\hline & & $(0.005)$ & $(0.003)$ & $(0.004)$ \\
\hline \multirow{2}{*}{$\begin{array}{c}\text { Pearson } \chi^{2} \\
p \text {-value }\end{array}$} & & 14.1 & 6.6 & 9.0 \\
\hline & & 0.015 & 0.252 & 0.110 \\
\hline
\end{tabular}

Note: Numbers parentheses are standard errors clustered by job id. The Pearson $\chi^{2}$ and associated $p$-value refer to a test of independence between age category and the measure of callback. Sample consists of 8,488 applications for 2,122 job postings.

simple comparison of means suggests that, while there are lower callback rates for very long unemployment spells (52 weeks), there is no systematic relationship between callback rates and unemployment duration for spells of one-half year or less.

\subsection{Age}

Table 5 contains mean callback rates for each of the three callback measures and each of the six age groups. The table also contains the results of Pearson $\chi^{2}$ tests of independence of callbacks and age category. While independence can be rejected for any-callbacks, there is not a monotone relationship between callbacks and age. It is clear that the callback rate is lower for the youngest (22-23 year old) and oldest (60-61 year old) applicants. The highest callback rate was received by 33-34 and 42-43 year old applicants. This inverted U-shape suggests that employers are most interested in hiring prime-age applicants for these jobs. The same general patters hold for information-callbacks and interview-callbacks, but the differences are not statistically significant. 
Table 6: Average Callback Rate, by Age and Number of Any-Callbacks

\begin{tabular}{c|cccc} 
& $(1)$ & $(2)$ & $(3)$ & $(4)$ \\
Age & $1-3$ Callbacks & 1 Callback & 2 Callbacks & 3 Callbacks \\
\hline $22-23$ & 0.310 & 0.204 & 0.378 & 0.520 \\
$27-28$ & $(0.027)$ & $(0.031)$ & $(0.050)$ & $(0.073)$ \\
& 0.407 & 0.203 & 0.512 & 0.800 \\
$33-34$ & $(0.026)$ & $(0.030)$ & $(0.042)$ & $(0.051)$ \\
& 0.486 & 0.319 & 0.621 & 0.815 \\
$42-43$ & $(0.028)$ & $(0.033)$ & $(0.049)$ & $(0.053)$ \\
& 0.472 & 0.275 & 0.568 & 0.833 \\
$51-52$ & $(0.028)$ & $(0.034)$ & $(0.047)$ & $(0.051)$ \\
& 0.407 & 0.256 & 0.509 & 0.717 \\
$60-61$ & $(0.027)$ & $(0.032)$ & $(0.046)$ & $(0.070)$ \\
& 0.387 & 0.238 & 0.406 & 0.796 \\
& $(0.029)$ & $(0.035)$ & $(0.050)$ & $(0.054)$ \\
\hline N Postings & 484 & 246 & 161 & 77 \\
Pearson $\chi^{2}$ & 26.4 & 9.1 & 17.2 & 18.9 \\
$p$-value & 0.000 & 0.107 & 0.004 & 0.002
\end{tabular}

Note: The callback rate is 0.25 for postings with 1 callback, 0.5 for postings with 2 callbacks, and 0.75 for postings with 3 callbacks. Standard errors clustered by job id are in parentheses. The Pearson $\chi^{2}$ and associated $p$-value refer to a test of independence between age category and any-callback.

As with unemployment duration, variation in age of applicant within job posting offers the opportunity to examine the relationship between callback rates and age. We focus again on the job postings for which there was variation in the outcome. We ignore the 1638 of 2122 job postings for which there was no variation in the outcome, and study the 484 postings with 1 to 3 callbacks. Again, for concision, we present results only for any-callback.

Table 6 contains mean any-callback rates by age for postings that received 1 to 3 callbacks conditioning on the number of callbacks. The inverted U-shaped pattern we found in the overall data is apparent in the callback rates conditional on the number of callbacks for postings with 1 and 2 callbacks. Callback rates are lowest for the youngest and oldest applicants. The pattern is strongest for applications to postings that received two callbacks. Among applications to postings that received 3 callbacks, the youngest applicants (age 2223) have substantially lower callback rates than older applicants, but there is no drop off in callback rates among the oldest applicants.

Overall, the estimates in table 6 conditioning on number of callbacks to a posting confirm the overall inverse U-shaped relationship between age and the callback rate. It appears that employers are less interested in hiring the youngest workers, perhaps because they have less 
experience. ${ }^{12}$ Employers also appear to be less interested in hiring the oldest job applicants (despite their having more experience).

\subsubsection{The Role of Experience for Young Applicants}

Interestingly, while existing audit studies on age (including our earlier work) have mainly focused on older applicants, our point estimates indicate that the youngest applicants have significantly lower callback rates relative to older applicants. As noted by Neumark, et al. (2015), when varying age, prior work experience must vary as well. Younger workers simply cannot have as much experience as older workers. To the extent that employers value prior work experience, the lower callback rates for the youngest applicants could be due to their having insufficient experience.

We investigate this directly using information in the posted job descriptions on recommended/required experience for the posted jobs. Of the 2,122 job postings that make up our analysis sample, 820 postings (38.6 percent) did not mention work experience, and 164 postings (7.7 percent) explicitly stated that no experience was required. Among the remaining 53.6 percent of postings that required at least some experience, 570 (26.9 percent of all postings) recommended/required one year or less experience, 491 (23.1 percent of all postings) recommended/required more than one year to 4 years experience, and 77 (3.6 percent of all postings) recommended/required more than 4 years experience (maximum 10). All of our applicants held a BA degree, implying that our youngest applicants (22-23 years old) could not have had more than a year or so of work experience at the time of application and, as a result, may be deemed unqualified for jobs requiring more experience.

Table 7 contains an analysis of overall callback rates by age category and the posted experience requirement. One obvious pattern is that callback rates are generally higher for applications to postings with no explicit mention of experience (first row of the table) for applicants 22-43. More generally, the table provides support for a strong interaction between age and posting experience recommendations/requirements in the relationship of callback rates with age. It is only for the youngest two age groups (22-23 and 27-28, estimates in columns 1 and 2 of table 7 ) that there is a statistically significant relationship between posted experience and the callback rate. These two age groups show very high callback

\footnotetext{
12 Fully 48 percent of 22-23 year old applicants have at least 12 weeks unemployment. This unemployment could be more salient (get a higher weight in the employer's inference process) for young workers due to their relative lack of experience and result in a lower callback rate. We address this directly in Section 4.2.2.
} 
Table 7: Average Callback Rate, by Recommended/Required Experience and Age

Rec/Req

(1)

(2)

(3)

(4)

(5)

\begin{tabular}{c|cccccc} 
Experience & Age 22-23 & Age 27-28 & Age 33-34 & Age 42-43 & Age 51-52 & Age 60-61 \\
\hline Exp N $/ A$ & 0.117 & 0.139 & 0.145 & 0.138 & 0.108 & 0.104 \\
& $(0.015)$ & $(0.015)$ & $(0.016)$ & $(0.016)$ & $(0.014)$ & $(0.014)$ \\
Exp $=0$ & 0.176 & 0.165 & 0.116 & 0.065 & 0.093 & 0.091 \\
& $(0.040)$ & $(0.035)$ & $(0.036)$ & $(0.024)$ & $(0.031)$ & $(0.034)$ \\
$0<\operatorname{Exp}<=1$ & 0.075 & 0.080 & 0.102 & 0.115 & 0.093 & 0.064 \\
& $(0.016)$ & $(0.014)$ & $(0.016)$ & $(0.018)$ & $(0.016)$ & $(0.013)$ \\
$1<\operatorname{Exp}<=4$ & 0.056 & 0.096 & 0.140 & 0.144 & 0.133 & 0.122 \\
& $(0.013)$ & $(0.016)$ & $(0.020)$ & $(0.021)$ & $(0.020)$ & $(0.020)$ \\
Exp $>4$ & 0.064 & 0.036 & 0.102 & 0.089 & 0.155 & 0.113 \\
& $(0.046)$ & $(0.025)$ & $(0.042)$ & $(0.042)$ & $(0.052)$ & $(0.044)$ \\
\hline All Exp & 0.094 & 0.111 & 0.129 & 0.126 & 0.110 & 0.097 \\
& $(0.009)$ & $(0.008)$ & $(0.009)$ & $(0.009)$ & $(0.009)$ & $(0.008)$ \\
\hline N Apps & 1304 & 1572 & 1460 & 1368 & 1439 & 1345 \\
Pearson $\chi^{2}$ & 18.7 & 16.6 & 4.8 & 4.4 & 6.3 & 7.3 \\
$p$-value & 0.001 & 0.002 & 0.307 & 0.179 & 0.358 & 0.121
\end{tabular}

Note: Standard errors clustered by job id are in parentheses. The Pearson $\chi^{2}$ and associated $p$-value refer to a test, within age category, of independence between experience category and any-callback.

rates to postings either with no statement of recommended/required experience or with an explicit statement of no experience required. It appears that employers posting jobs where experience is not important prefer younger applicants. Callback rates fall off sharply for younger applicants as recommended/required experience increases. There are not significant differences in callback rates by recommended/required experience for applicants 33 and older (columns 3-6 of table 7).

\subsubsection{Does the Effect of Unemployment Duration vary with Age?}

Recall that Kroft, et al. (2013) found a strong negative relationship between the likelihood of receiving a callback and unemployment duration among younger workers that was concentrated early in the unemployment spell. In contrast, Farber, et al. (2016, 2017) found no such relationship when considering older workers. Our current analysis (table 3), using a full spectrum of ages, suggests no relationship between the callback rate and unemployment duration for spells of unemployment up to 24 weeks but a lower likelihood of callback for very long unemployment spells (52 weeks). In this subsection, we examine the relationship between unemployment duration and the likelihood of callback separately by age group. 
Table 8: Average Callback Rate, by Unemployment Duration and Age

\begin{tabular}{c|c|ccc} 
& $(1)$ & $(2)$ & $(3)$ & $(4)$ \\
Weeks U & All Age & Age 22-23 & Age 27-52 & Age 60-61 \\
\hline 0 Weeks & 0.110 & 0.065 & 0.123 & 0.096 \\
& $(0.007)$ & $(0.013)$ & $(0.009)$ & $(0.016)$ \\
4 Weeks & 0.118 & 0.121 & 0.119 & 0.110 \\
& $(0.008)$ & $(0.019)$ & $(0.010)$ & $(0.018)$ \\
12 Weeks & 0.123 & 0.108 & 0.131 & 0.097 \\
& $(0.009)$ & $(0.021)$ & $(0.010)$ & $(0.020)$ \\
24 Weeks & 0.119 & 0.144 & 0.117 & 0.107 \\
& $(0.011)$ & $(0.027)$ & $(0.013)$ & $(0.022)$ \\
52 Weeks & 0.091 & 0.056 & 0.101 & 0.075 \\
& $(0.008)$ & $(0.016)$ & $(0.010)$ & $(0.016)$ \\
\hline F-Statistic & 2.89 & 3.80 & 1.39 & 0.62 \\
$p$-value & 0.021 & 0.005 & 0.235 & 0.065 \\
N Applications & 8488 & 1304 & 5839 & 1345
\end{tabular}

Note: Numbers parentheses are robust standard errors clustered by job id. The F-statistic and associated $p$-value refer to a test of equality of callback rates by unemployment duration within age category.

Our experimental design included six age groups. We showed in the previous subsection that there is virtually no difference in callback rates among the middle four age groups (2728, 33-34, 42-43, and 51-52). While we do not show the detailed results here, we verified that there are no significant patterns or differences in the relationship between callback rates and unemployment duration across these four age groups. To simplify the exposition, we proceed showing separately the relationships across 3 age groups (22-23, 27-52, and 60-61). We can think of these as young, prime-aged, and older applicants.

Table 8 presents the mean callback rates by unemployment duration both overall and for each of the three age categories. The first column of table repeats the means reported in column 1 of table 3 and shows the lower callback rate for applicants with 52 weeks unemployment. The callback rates in column 2 of the table are for the youngest applicants (22-23 years of age), and they show and inverted U-shape. Callback rates for young applicants with zero unemployment duration and with 52 weeks of unemployment are significantly and substantially lower than for those with 4-24 weeks of unemployment. The callback rates in column 4 of the table are for the oldest applicants (60-61 years of age), and they show a significantly lower callback rate for older applicants with 52 weeks unemployment. There are no significant distinctions in callback rates by weeks of unemployment for older applicants 
with 24 weeks or less unemployment. There are are no significant differences in callback rates by unemployment duration for the prime-aged applicants (column 3 of the table).

This analysis indicates that the difference in estimated duration dependence between Farber, et al. (2016, 2017) and Kroft et al. (2013) is likely not due to the fact that the two studies focused on different age groups. While we find a significantly lower callback rate at 52 weeks unemployment for the younger applicants in our study, there is not a general declining pattern of callback rates at lower durations of unemployment. In contrast, Kroft, et al. (2013) found a consistent negative relationship between the callback rate and duration for durations of 24 weeks or less. The contrast in results remains a puzzle.

\subsection{Interim Jobs}

Our experimental treatment of interim-job status included three values: 1) no interim job, 2) a lower quality interim job, and 3) a higher quality interim job. We do not have a clear expectation regarding the effect of holding an interim job of either type at the time of application on the likelihood of a callback. One question is whether an interim job is a good signal or a bad signal of worker quality. On the one hand, holding an interim job of any kind could be a positive signal of the applicant's drive or ambition and result in a higher likelihood of callback. On the other hand, a lower quality interim job could indicate that the applicant is lower quality and result in a lower likelihood of callback. If this channel is important we would expect that holding a lower quality interim job would reduce the likelihood of callback relative to otherwise-equivalent holders of a higher quality interim job. ${ }^{13}$

Another possibility is that employers find it easier to attract applicants (get them to accept a job offer) if the applicant is not employed. The fact that an applicant is employed might signal to an employer that the applicant's reservation wage is higher. As such, employers may prefer applicants who are not employed (no interim job). Alternatively, employers may be particularly concerned about pursuing applicants who are working in a higher-quality interim job but less concerned about pursuing applicants with no job or a lower-quality interim job.

Given our three-category treatment of interim jobs, almost any pattern of results can be understood in the context of these ideas. To summarize, define three probabilities of

\footnotetext{
${ }^{13}$ Note that, if employers update substantially based on an interim job, a natural inference is that employers weight current employment more heavily than past experience (all of which is in relatively high quality jobs) when forming an expectation of worker quality.
} 
Table 9: Average Callback Rate, by Interim Job Status

\begin{tabular}{c|r|ccc} 
Interim Job & N Apps & $\begin{array}{c}(1) \\
\text { Callback } \\
\text { (Any) }\end{array}$ & $\begin{array}{c}(2) \\
\text { Callback } \\
\text { (Information) }\end{array}$ & $\begin{array}{c}(3) \\
\text { Callback } \\
\text { (Interview) }\end{array}$ \\
\hline None & 2786 & 0.126 & 0.033 & 0.092 \\
& & $(0.007)$ & $(0.004)$ & $(0.006)$ \\
Lower Quality & 2861 & 0.102 & 0.027 & 0.075 \\
& & $(0.006)$ & $(0.004)$ & $(0.006)$ \\
Higher Quality & 2841 & 0.108 & 0.030 & 0.078 \\
& & $(0.007)$ & $(0.004)$ & $(0.006)$ \\
\hline All & 8488 & 0.112 & 0.030 & 0.082 \\
& & $(0.005)$ & $(0.003)$ & $(0.004)$ \\
\hline Pearson $\chi^{2}$ & & 8.8 & 2.3 & 6.4 \\
$p$-value & & 0.012 & 0.323 & 0.042
\end{tabular}

Note: Numbers parentheses are standard errors clustered by job id. The Pearson $\chi^{2}$ and associated $p$-value refer to a test of independence between interim job status and the measure of callback. Sample consists of 8,488 applications for 2,122 job postings.

callback: 1) $P_{n}=$ probability of callback if no interim job, 2) $P_{b}=$ probability of callback if lower-quality (bad) interim job, and 3) $P_{g}=$ probability of callback if higher-quality (good) interim job. Consider the following potential orderings:

- $P_{g}>P_{b}>P_{n}$ - Holding an interim job is a positive signal of workers quality, with a good interim job a better signal than a bad interim job.

- $P_{g}>P_{n}>P_{b}$ - Holding a good interim job is a positive signal of worker quality while holding a bad interim job is a negative signal.

- $P_{g}=P_{n}>P_{b}$ - Holding a good interim job is no particular signal of worker quality while holding a bad interim job is a negative signal.

- $P_{n}>P_{g}>P_{b}$ or $P_{n}>P_{g}=P_{b}$ - Holding any interim job is a signal to the employer that the applicant will be difficult/expensive to recruit.

Table 9 contains mean callback rates for each of the three callback measures and three interim job treatments. The table also contains the results of a Pearson $\chi^{2}$ test of independence of callbacks and interim job status. Independence can be rejected for any-callbacks and interview-callbacks, and the pattern is clear. The highest callback rates are for those applicants who hold no interim job. There is no statistically significant difference between 
Table 10: Average Callback Rate, by Interim Job Status and Number of Any-Callbacks

\begin{tabular}{c|cccc} 
& $(1)$ & $(2)$ & $(3)$ & $(4)$ \\
Interim Job & 1-3 Callbacks & 1 Callback & 2 Callbacks & 3 Callbacks \\
\hline None & 0.461 & 0.281 & 0.559 & 0.806 \\
Lower Quality & $(0.019)$ & $(0.020)$ & $(0.030)$ & $(0.033)$ \\
& 0.385 & 0.212 & 0.509 & 0.699 \\
Higher Quality & $(0.018)$ & $(0.019)$ & $(0.027)$ & $(0.039)$ \\
& 0.391 & 0.256 & 0.427 & 0.738 \\
& $(0.017)$ & $(0.019)$ & $(0.026)$ & $(0.037)$ \\
\hline N Postings & 484 & 246 & 161 & 77 \\
Pearson $\chi^{2}$ & 9.6 & 4.3 & 7.5 & 3.2 \\
$p$-value & 0.008 & 0.120 & 0.023 & 0.207
\end{tabular}

Note: The callback rate is 0.25 for postings with 1 callback, 0.5 for postings with 2 callbacks, and 0.75 for postings with 3 callbacks. Standard errors clustered by job id are in parentheses. The Pearson $\chi^{2}$ and associated $p$-value refer to a test of independence between interim job status and any-callback.

callback rates for lower- and higher-quality interim job holders. The same general pattern holds for information-callbacks, but the differences are not statistically significant.

Table 10 contains mean any-callback rates by interim job status for postings that received 1 to 3 callbacks conditioning on the number of callbacks. The general pattern is the same as the unconditional results in table 9 . In every case, the highest callback rate is associated with holding no interim job. However, independence of the callback rate and interim job status is rejected only for the combined postings receiving 1-3 callbacks and the set of applications to postings with 2 callbacks. There is no consistent distinction between the callback rates for applications with lower- and higher-quality interim jobs.

\subsection{Interim Jobs and the Skill Level of the Position}

As we noted earlier, we classified the job posting to which we submitted résumés as "lowskill" and "high-skill." Given that our applicants' interim jobs also were "low" or "high" quality, it may be that the effect of holding an interim job of a given type could have differing relationships with the callback rate depending on the type of job for which the application is made.

We start by validating our categorization of job postings as low-skill or high-skill using information we collected on any stated education requirements or preferences in the job description. The distributions of these characteristics are summarized in table 2. Table 11 
Table 11: Distribution of Stated Education Preference/Requirement, By Skill of Posted Job

\begin{tabular}{c|ccccc} 
& $(1)$ & $(2)$ & $(3)$ & $(4)$ & $(5)$ \\
Job Skill & $\mathrm{N}$ & High School & Associate & Bachelors & No Listing \\
\hline Low Skill & 2872 & 0.305 & 0.056 & 0.049 & 0.591 \\
High Skill & 5616 & 0.266 & 0.107 & 0.143 & 0.484 \\
\hline All & 8488 & 0.279 & 0.090 & 0.111 & 0.520
\end{tabular}

Note: The proportions are row fractions based on a text analysis of the job postings. The posts are classified as low- and high-skill as described earlier and summarized in table 2 .

Table 12: Average Callback Rate, by Interim Job Status and Position Quality

\begin{tabular}{c|c|c|ccc|c} 
Position & \multirow{2}{*}{ N Apps } & $\begin{array}{c}(1) \\
\text { All }\end{array}$ & $\begin{array}{c}(2) \\
\text { No }\end{array}$ & $\begin{array}{c}\text { Lower Qual } \\
\text { Interim Job }\end{array}$ & $\begin{array}{c}\text { Higher Qual } \\
\text { Interim Job }\end{array}$ & $\begin{array}{c}(5) \\
\text { Interim Job } \\
\chi^{2} \\
\text { [p-value }]\end{array}$ \\
\hline Lower Qual & 2872 & 0.101 & 0.109 & 0.105 & 0.090 & 2.0 \\
& & $(0.008)$ & $(0.011)$ & $(0.011)$ & $(0.010)$ & {$[0.369]$} \\
Higher Qual & \multirow{2}{*}{5616} & 0.117 & 0.134 & 0.100 & 0.117 & 10.6 \\
& & $(0.006)$ & $(0.010)$ & $(0.008)$ & $(0.009)$ & {$[0.005]$} \\
\hline All & \multirow{2}{*}{8488} & 0.112 & 0.126 & 0.102 & 0.108 & 8.8 \\
& & $(0.005)$ & $(0.007)$ & $(0.006)$ & $(0.007)$ & {$[0.012]$}
\end{tabular}

Note: Numbers parentheses are standard errors clustered by job id. The Pearson $\chi^{2}$ in column (5) and associated [ $p$-value] refer to a test of independence between interim job status and callback for each quality-of-position group. Sample consists of 8,488 applications for 2,122 job postings.

contains a cross-tabulation of the skill level of the 8,488 job postings with information in the job description regarding preferences for or requirements of a specific education level. Over half the postings did not list an education level, but among those that did list an education level, the high-skill postings were more likely to list a bachelor's or associate's degree (48.5 percent of the high-skill listings with a stated education level) relative to the low-skill postings (25.7 percent of the low-skill listings with a stated education level). This lends some support to our assignment of postings to the low- and high-skill categories.

Table 12 contains mean any-callback rates by interim job status and skill level of the posted position. There is no significant relationship between callbacks and interim job status for the applications to the lower quality positions (mostly receptionists, office assistants, and clerical/data entry positions). However, among applications for higher quality positions (mostly administrative and executive assistants and office managers), there is a strong pattern. Holding an interim job of either lower or higher quality results in a significantly lower callback rate relative to those applicants who are unemployed at the time of application. 
Overall, the analysis of interim-job status supports the view that employers, particularly those hiring into relatively high-skilled positions, prefer to hire those applicants who are not employed. As we noted earlier, this is consistent with findings in the literature by Kroft, et al. (2013), Farber, et al. (2016, 2017), and Nunley, et al. (2017), and it suggests that employers seeking to fill at least the type of jobs we consider here prefer to hire the unemployed, perhaps because of a perception that they will be easier/cheaper to recruit. ${ }^{14}$ The evidence in table 12, that the preference for the unemployed exists only for applications to the more highly skilled positions is weakly consistent with this argument since costs of recruitment are likely higher for higher quality jobs.

\subsection{Multivariate Analysis}

We now turn to a multivariate logit analysis that models the probability of a callback as a function of unemployment duration, age, and interim job status as well as posting-specific characteristics including skill level and education preference/requirement. This analysis first uses both within- and between-posting variation in application characteristics. We choose the logit model for several reasons. In principle, it should provide a better approximation of the functional form for binary choice probabilities with a relative low incidence. ${ }^{15}$ Given the canonical sample design of recent audit studies that provide random variation within postings, a particular advantage of the logit model is that it provides a consistent approach that allows us to obtain estimates for that rely on within-posting variation via the Chamberlain (1980) fixed-effects logit model. Finally, the logit model allow us to contrast the fixed-effect estimator with a random-effects logit estimator, which is our preferred specification.

The random-effects model accounts for the fact that job postings are randomly drawn from the underlying population and may differ in their mean callback rate. This model is appropriate (yields consistent estimates) where the baseline variation across job postings in their callback rates is uncorrelated with the observed applicant characteristics of interest. Given our approach in sending resumes to job listings with key characteristics varying

\footnotetext{
${ }^{14}$ While the findings in the literature pertain to a broader groups of job applicants, a particular note of caution regarding the external validity of this interpretation is warranted. Employers for other more skilled jobs may prefer to hire workers who are employed and so be willing to go through the difficulty and bear the expense of attracting the employed.

15 We have reproduced the logit findings with linear probability and probit models, and the results are not affected by the choice of functional form.
} 
randomly, we would not expect the job-specific callback rate to be correlated with resume characteristics so that estimates derived using the random-effects model should be consistent. More generally, since the treatments were assigned independently to resumes, there is no reason to expect that the multivariate analysis in general, and the conditional logit in particular, will affect our main results.

Table 13 presents the main results of our multivariate analysis of the probability of anycallback. We report our findings in terms of odds ratios, which for small probabilities are approximately the ratio of probabilities of callback given a treatment vs. a base condition. ${ }^{16}$ An odds ratio greater than one implies that the associated factor increases the likelihood of a callback relative to the base group. Similarly, an odds ratio less than one implies that the associated factor decreases the likelihood of a callback relative to the base group. The base group in the table consists of applicants aged 27-52 with zero weeks unemployment and no interim job. ${ }^{17}$

The first column of table 13 presents results for the basic logit model with controls for weeks of unemployment, age, and interim job status. These results confirm our earlier univariate findings. Applicants with 52 weeks of unemployment have a significantly lower, by about 19 percent, probability of a callback (odds ratio significantly less than one) than applicants with less unemployment. There are no significant differences in callback rates among the unemployment durations shorter than 52 weeks. Both the youngest (22-23 years old) and oldest (60-61 years old) applicants have callback rates about 75-80 percent as large as prime age applicants. ${ }^{18}$ Finally, holders of a lower-quality interim job have a 20 percent lower probability of a callback while holders of a higher-quality interim job have about a 15 percent lower probability of callback.

The logit model whose results are presented in column 2 of the table additionally includes controls for characteristics of the job posting. These include indicators for the skill level of

\footnotetext{
${ }^{16}$ Let $p(1) \equiv \operatorname{Pr}\{$ Callback $=1 \mid X, D=1\}$ and $p(0) \equiv \operatorname{Pr}\{$ Callback $=1 \mid X, D=0\}$, where $D$ represents one of our right hand side dummy variables, and $\mathrm{X}$ represents the remaining variables in the model. Then the odds ratio $R$ is defined as $R \equiv \frac{p(1) /(1-p(1))}{p(0) /(1-p(0))}=\exp \left\{\beta_{D}\right\}$, where $\beta_{D}$ is the coefficient on $D$. Where the probabilities involved are small, the odds ratio is approximately the ratio of probabilities $\left(\frac{p(1)}{p(0)}\right)$.

17 Given the earlier results on age, we simplified the estimation by combining the 27-28, 33-34, 42-43, and 51-52 year old applicants. There were no distinctions in callback rates among these groups. See tables 5 and 6 .

18 As we noted earlier (see table 7 and supporting discussion), the lower callback rate for the youngest applicants is due to the fact that these applicants have very low callback rates to jobs that require prior experience. We explore this further below.
} 
Table 13: Logit Model Estimates of Any-Callback Probability : Odds Ratios Logit, Random-Effects Logit, and Fixed-Effect Logit Models

\begin{tabular}{l|ccccc} 
& $(1)$ & $(2)$ & $(3)$ & $(4)$ & $(5)$ \\
Variable & Logit & Logit & RE Logit & RE Logit & FE Logit \\
\hline Applicant Characteristics: & & & & & \\
4 Weeks U & 1.093 & 1.085 & 1.012 & 1.005 & 0.946 \\
& $(0.106)$ & $(0.105)$ & $(0.142)$ & $(0.141)$ & $(0.141)$ \\
12 Weeks U & 1.126 & 1.100 & 1.194 & 1.173 & 1.151 \\
& $(0.113)$ & $(0.111)$ & $(0.168)$ & $(0.165)$ & $(0.172)$ \\
& 1.105 & 1.078 & 1.038 & 1.020 & 0.963 \\
52 Weeks U & $(0.136)$ & $(0.133)$ & $(0.175)$ & $(0.172)$ & $(0.175)$ \\
Age 22-23 & 0.812 & 0.800 & 0.637 & 0.631 & 0.610 \\
Age 60-61 & $(0.087)$ & $(0.086)$ & $(0.096)$ & $(0.095)$ & $(0.096)$ \\
& 0.767 & 0.761 & 0.580 & 0.579 & 0.563 \\
Low Interim Job & $(0.076)$ & $(0.076)$ & $(0.080)$ & $(0.080)$ & $(0.079)$ \\
High Interim Job & 0.792 & 0.789 & 0.747 & 0.745 & 0.786 \\
& $(0.077)$ & $(0.077)$ & $(0.101)$ & $(0.101)$ & $(0.109)$ \\
& 0.790 & 0.794 & 0.711 & 0.713 & 0.727 \\
& $(0.067)$ & $(0.067)$ & $(0.084)$ & $(0.084)$ & $(0.090)$ \\
& 0.844 & 0.847 & 0.742 & 0.743 & 0.740 \\
& $(0.073)$ & $(0.074)$ & $(0.088)$ & $(0.088)$ & $(0.094)$ \\
\hline
\end{tabular}

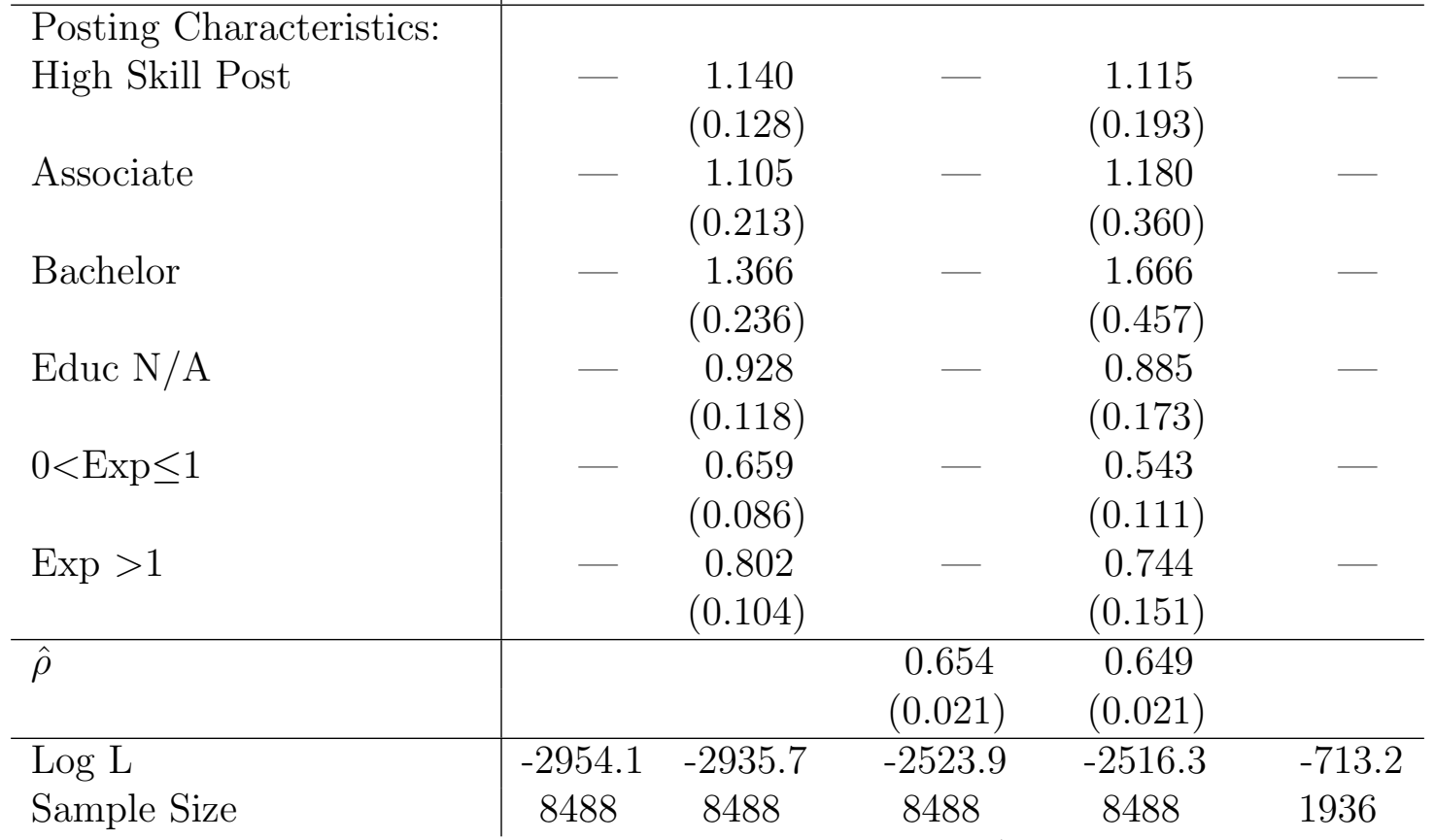

Note: Numbers in parentheses are asymptotic standard errors (clustered at the job-posting level in columns 1 and 2). The base group consists of applicants with zero weeks unemployment, aged 27-52, and no interim job. The base group in columns 2 and 4 additionally is characterized as a low-skill posting with high school education recommended/required and zero experience recommended/required or no statement regarding experience. 
the posted job, the stated educational recommendation/requirement, and the stated experience recommendation/requirement. Unlike the characteristics of the applicants, these are characteristics of the job posting and, thus, have no within-posting variation. As expected, none of the estimated odds ratios for our treatment variables (unemployment, age, interim job) are affected in any meaningful way by inclusion of the job posting characteristics. The likelihood of callback is not significantly related to the skill level of the posting or the stated education level. ${ }^{19}$ However, the likelihood of callback is clearly higher for job postings with a zero experience recommendation/requirement or no statement regarding experience.

It is worth noting that the lower callback rate for the youngest applicants is unaffected by controlling for the stated experience recommendation/requirement (column 2). However, this specification constrains the effect of posted experience to be the same across applicant age groups. We relax this constraint below in order to examine whether the lower callback rate for very young applicants is due to the fact, noted above, that these applicants cannot have much prior experience.

Columns 3 and 4 of table 13 contain estimates of the random-effects logit versions of the specifications in the first two columns of the table. The estimated within-posting crossobservation correlation in the error $(\hat{\rho}=0.65$, s.e. $=0.021)$ along with the substantial improvement in the log-likelihood when accounting for the random effect strongly implies that there are important posting-specific factors affecting callback rates. Given the similar correlation of the unobserved posting-specific factors in column 4 of the table, it is clear that these posting-specific factors go beyond the skill level of the posted job and the stated required/recommended education and experience levels. This reflects the reality that different employers have different callback rates. This is corroborated by the fact that fully 75 percent of our postings gave no callback to any of the 4 résumés submitted.

The random-effects estimates of the parameters of interest are very similar to the standard logit estimates and show the same patterns. This is to be expected given that the treatments were assigned randomly to job postings. One small contrast is that the random-effects estimates suggest that the youngest applicants are at an even larger disadvantage, with 2223 year old applicants having a callback rate about 40 percent lower than prime age workers. Similarly, the interim job penalty in callback rates is larger in the random-effects model.

\footnotetext{
19 Note that statistical tests of signficance here use $p$-values based on a test of the hypothesis that the estimated coefficient of the logit model is zero and not the test that the odds-ratio transformation of this coefficient is significantly different from one.
} 
Finally, column 5 of table 13 contains the estimates of the Chamberlain fixed-effects logit model. The sample is limited to the 1,936 applications to the 484 job posting where there was variation in the outcome ( 1 to 3 callbacks). The 6,404 applications to the 1,601 postings that received no callbacks and the 148 applications to the 37 postings that received four callbacks are not included. As expected, given random assignment, the fixed-effect estimates of the odds ratios are virtually identical to the random-effects estimates in column 3.

Overall, the results in Table 13 confirm our main findings. First, there is no difference in callback rates by weeks of unemployment for those unemployed 24 weeks or less. However, applicants who were unemployed for 52 weeks did have a lower callback rate. Second, the youngest (22-23) and oldest applicants (60-61) have lower callback rates than prime-age applicants. Finally, holding an interim job, regardless of quality, at the time of application results in lower callback rates.

Next, we estimate the random-effects logit model of the probability of any-callback allowing the effects of unemployment duration, and employment status at the time of application to vary with age. We also take this opportunity to allow age differences in callback rates to vary with the stated experience recommendations/requirements. This model is a less constrained version of the random-effects logit model in column 4 of table 13, and its estimates are presented in table 14. The interpretation of this table requires a bit of explanation. All estimates in the table are from the same logistic regression model. The first column of table 14 contains the odds ratios for the indicated category relative to a baseline consisting of applicants aged 27-52 with zero weeks unemployment and no interim job who have applied for a low-skill posting with a high school education recommended/required and zero experience recommend/required or no statement regarding experience. The estimates show that, at baseline relative to prime age applicants (27-52), the youngest applicants (age 22-23) have a marginally significantly lower likelihood of callback, and postings that recommend/require a 4-year college degree have marginally significantly higher callback rates.

The estimates in columns 2-4 of table 14 show the odds ratios separately by age category for weeks of unemployment, interim job status, and the recommended/required experience level relative to applicants at the baseline with zero weeks unemployment, no interim job, and relative to postings zero experience recommended/required or no statement regarding experience. ${ }^{20}$ These estimates allow us to examine whether the patterns we found earlier in

\footnotetext{
${ }^{20}$ Note that the odds ratios in columns 2-4 are derived from underlying coefficient estmates that capture the difference in the marginal effect for the interaction relative to the baseline group in column 1.
} 
Table 14: Estimates of Any-Callback Probability, with Treatments interacted with Age Random-Effects Logit Model: Odds Ratios

\begin{tabular}{|c|c|c|c|c|c|}
\hline Variable & $\begin{array}{c}(1) \\
\text { Baseline }\end{array}$ & Variable & $\begin{array}{c}(2) \\
\text { Age } 22-23\end{array}$ & $\begin{array}{c}(3) \\
\text { Age } 27-52\end{array}$ & $\begin{array}{c}(4) \\
\text { Age } 60-61\end{array}$ \\
\hline \multirow[t]{2}{*}{ Age $22-23$} & 0.610 & 4 Weeks U & 1.878 & 0.965 & 0.716 \\
\hline & $(0.233)$ & & $(0.705)$ & $(0.161)$ & $(0.257)$ \\
\hline \multirow[t]{2}{*}{ Age 60-61 } & 0.826 & 12 Weeks U & 1.665 & 1.244 & 0.577 \\
\hline & $(0.298)$ & & $(0.683)$ & $(0.204)$ & $(0.230)$ \\
\hline \multirow[t]{2}{*}{ High Skill Post } & 1.121 & 24 Weeks U & 3.044 & 0.904 & 0.703 \\
\hline & $(0.195)$ & & $(1.315)$ & $(0.183)$ & $(0.287)$ \\
\hline \multirow[t]{2}{*}{ Associate } & 1.189 & 52 Weeks U & 0.466 & 0.700 & 0.446 \\
\hline & $(0.365)$ & & $(0.220)$ & $(0.123)$ & $(0.178)$ \\
\hline \multirow[t]{2}{*}{ Bachelor } & 1.668 & Low Interim Job & 0.593 & 0.682 & 0.964 \\
\hline & $(0.462)$ & & $(0.200)$ & $(0.095)$ & $(0.292)$ \\
\hline \multirow[t]{5}{*}{ Educ N/A } & 0.881 & High Interim Job & 0.628 & 0.734 & 0.843 \\
\hline & $(0.174)$ & & $(0.202)$ & $(0.103)$ & $(0.272)$ \\
\hline & & $0<\mathrm{YR} \leq 1$ Exp Req & 0.450 & 0.584 & 0.440 \\
\hline & & $>1 \mathrm{YB}$ Fyn $\mathrm{Beq}$ & $(0.163)$ & $(0.127)$ & $\begin{array}{c}(0.164) \\
1.200\end{array}$ \\
\hline & & & $(0.100)$ & $(0.167)$ & $\begin{array}{l}1.29 \\
(0.410)\end{array}$ \\
\hline$\hat{\rho}$ & $\begin{array}{c}0.655 \\
(0.021)\end{array}$ & $\begin{array}{l}\log \mathrm{L}=-2500.4 \\
N=8488 \text { Apps }\end{array}$ & & & \\
\hline
\end{tabular}

Note: Numbers in parentheses are asymptotic standard errors. The estimates in column 1 are odds ratios relative to a baseline group consisting of applicants aged 27-52 with zero weeks unemployment and no interim job who have applied for a low-skill posting with a high school education recommended/required and zero experience or no statement of experience recommended/required. The estimates in columns 2-4 are odds ratios by age relative to the baseline group with zero weeks unemployment and no interim job.

the relationships between the likelihood of callback and these treatments varies by age.

A likelihood-ratio test, based on a comparison of the estimates of the relevant constrained and unconstrained models, of the hypothesis that the effect of unemployment duration on callback does not vary by age is marginally rejected at conventional levels ( $p$-value $=0.048)$. The estimates reported in table 3 and table 13 showed that applicants with 52 weeks unemployment had lower callback rates than applicants with shorter unemployment spells but that there were no differences in callback rates across the shorter spells. The estimates in columns 2-4 of table 14 allow us to examine further whether this pattern varies by age of applicant. These are the multivariate analog of the simple tabulations in table 8 , and they show a similar pattern. In every age group, those applicants with 52 weeks unemployment have significantly lower callback rates than workers with shorter spells of unemployment, but 
there are no significant distinctions by duration of unemployment among applicants with less than 52 weeks of unemployment. Hence, while our data does not reject that there are slght variations in the effect of unemployment duration by age, there is no evidence here that variation in the relationship between unemployment duration and callback rates by age can account for the differences in results found in previous studies.

The analogous likelihood-ratio test of the hypothesis that the effect of interim job status on callback does not vary by age is not rejected $(p$-value $=0.84)$. The estimates reported in table 9 and table 13 showed a negative relationship between the likelihood of callback and holding an interim job of either lower or higher quality. The estimates in columns 2-4 of table 14 allow us to examine further whether this pattern varies by age of applicant. These estimates confirm the negative relationship we reported earlier for the youngest and prime-age applicants. However, there appears to be no relationship between the likelihood of callback and interim job status for the oldest applicants.

The multivariate analyses presented in table 13 constrained the effect of applicant age to be constant across postings with different experience recommendations/requirements. This is not consistent with our finding (table 7) that the youngest applicants had high callback rates to jobs with little or no experience recommended/required and low callback rates to

jobs with more experience recommended/required. Table 14 contains the estimates of the random-effects logit model without this constraint. Not surprisingly, a likelihood-ratio test of the hypothesis that the effect of the stated experience recommendation/requirement on callbacks does not vary by age is easily rejected at conventional levels ( $p$-value $=0.004)$. The estimates clearly show that odds of a callback are sharply lower as the experience recommendation/requirement increases. This is not surprising, and it accounts for at least part of the deficit in callback rates for the youngest applicants that we found in table 13 .

\section{$5 \quad$ Final Remarks}

The rise and stubborn persistence of long-term unemployment after the Great Recession has motivated a series of audit studies to investigate the determinants of successful job applications. Those studies have generated a variety of results, some of which indicate that age, duration of unemployment, and recent employment history might interact in important ways to influence job application outcomes. To explore those interactions, we fielded a new audit study varying treatments of unemployment duration, age, and the current employment 
status of the applicant.

The results indicate duration dependence in callbacks only after very long spells of unemployment. This contrasts our own previous findings (Farber et al. 2016, 2017) of no duration dependence, and also contrasts with the results of Kroft et al. (2013) who found duration dependence only in the first few months of unemployment. The results reported here are closest to those in Eriksson and Rooth (2014), who found duration dependence of callback rates only after nine months of unemployment.

A simple model of employer learning suggests that older applicants may be at least partially immunized against any stigmatizing effects of long unemployment spells due to having a more substantial work history relative to younger applicants. This immunizing effect of age has the potential to help explain the differing results among prior audit studies. While we do find significant effects of age on callback rates, there is little evidence of an important interaction between age and unemployment duration in the effect on the likelihood of callback; we cannot reject a null hypothesis of no differences by age in the relationship between unemployment duration and the callback rate. Thus, there is little reason to think that differences in the age of applicants can explain the different results in previous studies.

Our findings do, however, offer insight into a variety of prior results regarding callback rates for the currently employed. Echoing elements of our prior study, Kroft et al. (2013), and Nunley et al. (2017), we find that average callback rates are significantly higher for the unemployed than for those holding an interim job. Importantly we show here that this negative effect of employment holds regardless of the quality of the interim job, but obtains only when applying to a relatively high-skilled position. These results, which indicate some unappreciated challenges of on-the-job search, merit further investigation.

More generally, the variation we observe in some of the qualitative conclusions of audit studies with very similar designs suggests caution in interpreting their results as being generally applicable to other settings. It appears that seemingly small differences in markets, occupations, résumé designs, and other factors can cause substantial differences in how callback rates vary in important dimensions. In this way, inference from audit studies would seem to require more than the usual attention to replication and assessment of external validity. 


\section{References}

Bendick, Marc, Jr., Charles W. Jackson, and J. Horacio Romero. "Employment Discrimination Against Older Workers: An Experimental Study of Hiring Practices," Journal of Aging ES Social Policy, 8 (1997), pp. 25-46.

Bertrand, Marianne and Sendhil Mullainathan. "Are Emily and Greg More Employable than Lakisha and Jamal? A Field Experiment on Labor Market Discrimination," American Economic Review, 94 (2004), 991-1013.

Bowlus, Audra J. "Matching workers and jobs: Cyclical fluctuations in match quality." Journal of Labor Economics 13 (2)(1995) pp. 335-350

Chamberlain, Gary. "Analysis of Covariance with Qualitative Data," Review of Economic Studies, 47(1) (1980), 225-238.

Chan, Sewin, and Ann Huff Stevens. "Job Loss and Employment Patterns of Older Workers." Journal of Labor Economics 19, no. 2 (2001): 484-521.

Eriksson, Stefan and Dan-Olof Rooth. "Do employers use unemployment as a sorting criterion when hiring? Evidence from a field experiment," American Economic Review, 104 (2014), 1014-1039.

Farber, Henry S. "Alternative and Part-Time Employment Arrangements as a Response to Job Loss," Journal of Labor Economics 17:S4 (1999), S142-S169

Farber, Henry S. "Employment, Hours, and Earnings Consequences of Job Loss: U.S. Evidence from the Displaced Workers Survey," Journal of Labor Economics, 35(S1) (July 2017), pp. S235-S272.

Farber, Henry S., Dan Silverman, and Till von Wachter. "Determinants of Callbacks to Job Applications: An Audit Study," American Economic Review, 106(5) May 2016, pp. 314-318.

Farber, Henry S., Dan Silverman, and Till von Wachter. "Factors Determining Callbacks to Job Applications by the Unemployed: An Audit Study," RSF: The Russell Sage Foundation Journal of the Social Sciences, 2017.

Ghayad, Rand. "The Jobless Trap." mimeo, Northeastern University, 2014.

Jarosch, Gregor and Laura Pilossoph. "Statistical Discrimination and Duration Dependence in the Job Finding Rate," mimeo, Stanford University, September 2016. 
Kahn, Lisa B. "The long-term labor market consequences of graduating from college in a bad economy," Labour Economics 17(2) (2010), pp. 303-316.

Kroft, Kory, Fabian Lange, and Matthew J. Notowidigdo. "Duration Dependence and Labor Market Conditions: Evidence from a Field Experiment," Quarterly Journal of Economics 129(2) (August 2013) pp. 1123-1167.

Lahey, Joanna N., "Age, Women, and Hiring: An Experimental Study," Journal of Human Resources, 43 (2008), 30-56.

Neumark, David, Ian Burn, and Patrick Button. "Is it Harder for Older Workers to Find Jobs: New and Improved Evidence from a Field Study, Working Paper 21669, National Bureau of Economic Research, October 2015. Journal of Political Economy, in press.

Neumark, David, Ian Burn, and Patrick Button. "Experimental Age Discrimination Evidence and the Heckman Critique," American Economic Review 106(5) (May 2016), 303-308.

Nunley, John M., Adam Pugh, Nicholas Romero, and Richard Alan Seals, Jr., "Unemployment, Underemployment, and Employment Opportunities: Results from a Correspondence Audit Study of the Labor Market for College Graduates." Industrial and Labor Relations Review, 70(3) (2017), pp. 642-669.

Oreopoulos, Phil, Andrew Heitz, and Till von Wachter. "The Short- and Long-Term Career Effects of Graduating in a Recession: Hysteresis and Heterogeneity in the Market for College Graduates," American Economic Journal: Applied Economics, 4(1) (January 2012), pp. 1-29.

Schwandt, Hannes and Till von Wachter. "Unlucky Cohorts: The Long-Term Effects of Entering the Labor Market in a Recession on Earnings and Health," Working Paper, April 2017.

Song, Jae and Till von Wachter. "Long-Term Nonemployment and Job Displacement." In: Evaluating Labor Market Dynamics, A Symposium Sponsored by the Federal Reserve Board of Kansas City, Jackson Hole, Wyo., August 2014.

Stevens, Ann Huff. "Persistent Effects of Job Displacement: The Importance of Multiple Job Losses," Journal of Labor Economics 15 (1, Part 1) (1997), pp. 165-188.

Von Wachter, Till, Jae Song, and Joyce Manchester. "Long-Term Earnings Losses Due to Mass Layoffs during the 1982 Recession: An Analysis Using US Administrative Data from 1974 to 2004." Working Paper, 2009. 


\section{Appendix - Sample Cover Letters and Resumes}

This appendix contains a set of three sample cover letters and resumes.

1. Heather Adams, Chcago, 52 weeks unemployment, middle aged, high-level interim job.

2. Rose Peters, Chicago, 12 weeks unemployment, younger, low-level interim job.

3. Donna Ramsey, Chicago, 4 weeks unemployment, younger, no interim job. 
Heather Adams

232 North Lind Avenue

Hillside, IL 60192

(708) 616-4600

heather61376@gmail.com

February 22, 2017

Dear Sir or Madam:

My name is Heather Adams and I am writing in response to your request for an Administrative Assistant. The qualities, education and experience I possess are perfectly suited for the position described, and I am sure I would make an excellent candidate for the job.

For the past ten years, I have worked in the administrative field where my responsibilities included: office management and inventory duties; heavy data entry and formatting; regular correspondence tasks for my employers; and effective in-person interaction with clients, fellow employees and employers alike. I have managed intensive multi-line telephone systems and have become familiar with a variety of computer programs. The time I spent in administration has given me the skills I need to be an efficient, detail oriented, interpersonally-skilled assistant, and I am looking forward to applying these skills to this new job opportunity.

In addition to over a decade of pertinent experience, my Bachelors degree in English gives me an edge as it has trained me to be an excellent communicator with great writing skills. As an Administrative Assistant, these skills allow me to engage comfortably and articulately with clients even in high-stress situations and to handle any writing or editing assignment given to me with ease.

Please see my attached resume for further details about my past experience, and feel free to contact me, by phone ((708) 616-4600) or email (heather61376@gmail.com), with any questions at all. I would also be happy to provide references from any former supervisors. I look forward to hearing from you soon and to meeting in person for an interview.

Respectfully yours,

Heather Adams 


\section{Heather Adams}

232 North Lind Avenue

Hillside, IL 60192 heather61376@gmail.com

(708) 616-4600

WORK EXPERIENCE

\section{VelocityEHS}

Executive Assistant
Chicago, IL

August 2017 - Present

- Coordinate with external investment and alliance managers for authorized signatories on accounts

- Pull financial statements from investment and manager website portal

- Create and post of weekly and monthly investment performance reports

MSDS Online

Chicago, IL

Administrative Assistant

March 2016 - August 2016

- Capably handled filing, faxing and copying tasks on a daily basis

- Wrote, proofread, and made letters signature-ready

- Professionally answered numerous phone calls using multi-line phones

- Copied and filed signed letters before returning to originator

- Handled scheduling and change of appointments for a very busy Executive Director

- Provided monthly printer counts, inventoried printer cartridges and toners, supplied buy list to IT personnel, and packaged and labeled empty printer cartridges/toners for shipping back to manufacturer for recycling

Superior Employment Agency

Administrative Support
Chicago, IL

June 2012 - March 2016

- Printed CD labels and oversaw burning, scanning, and distribution of company CDs

- Created roster sign-in sheets in PDF format and updated roster sheets in Excel

- Updated files and books as needed for classes

- Formatted documents, adding page numbers, watermarks, and using a PDF Converter

- Edited PowerPoint presentations

Bethel Employment Center

Administrative Assistant
Chicago, IL

March 2007 - June 2012

- Responsible for day-to-day secretarial needs: took dictation; typed letters, memos, reports; screened telephone calls; attended meetings; scheduled conference calls

- Managed daily administrative needs of Marketing and Operations Departments including maintenance of Microsoft Outlook calendars, coordination of travel arrangements, inoffice meeting planning, and out-of-office meeting planning

- Answered multi-line telephone system and directed calls to appropriate staff

- Pre-interviewed visitors and guests as instructed

- Summarized research and prepared informational packets for staff dissemination

- Greeted internal and external clients and opened correspondence

- Maintained conference rooms and scheduled meetings and handled all travel arrangements

- Attended monthly board meetings, prepared minutes, illustrated monthly newsletters, handled in-unit billing and petty cash, and provided front desk coverage 
- Disseminated all correspondence and memos

- Supported building manager and other staff with prompt professionalism

EDUCATION

Northern Illinois University

DeKalb, IL

B.A. English

June 2005

\section{SKILLS}

- Proven ability to work in fast-paced environment

- Detail oriented and capable of multi-tasking

- Excellent communication and language skills

- Adept at PowerPoint, Word, Excel and PDF editing 
Rose Peters

3313 Tucker St

209 Chandler Ave

Elmhurst, IL 60126

(708) 714-0986

peterssrose@gmail.com

$3 / 1 / 2017$

Dear Sir or Madam:

I am writing in response to your request for an Office Assistant / Business Administrator. The qualities, education and experience I possess are perfectly suited for the position described, and I am sure I would make an excellent candidate for the job.

For over five years, I have worked in the Administrative field where my responsibilities included: office management and inventory duties; heavy data entry and formatting; regular correspondence tasks for my employers; and effective in-person interaction with clients, fellow employees and employers alike. I have managed intensive multi-line telephone systems and have become familiar with a variety of computer programs. The time I spent in administration has given me the skills I need to be an efficient, detail oriented, interpersonally-skilled assistant, and I am looking forward to applying these skills to this new job opportunity.

Please see my attached resume for further details about my past experience, and feel free to contact me, by phone or email, with any questions at all. I would also be happy to provide references from any former supervisors. I look forward to hearing from you soon and to meeting in person for an interview.

Respectfully yours,

Rose Peters 


\section{Rose Peters}

209 Chandler Ave

Elmhurst, IL 60126 peterssrose@gmail.com

(708) 714-0986

WORK EXPERIENCE

Ben \& Jerry's

Sales Associate
Evanston, IL

August 2017 to Present

- Developed proficiency in working with high volumes of customers

- Work through customer concerns and complaints in both simple and difficult situations

- Developed skills to work as a team to accommodate customers while maintaining the facility

AIS-comp Inc.

Chicago, IL

Executive Assistant to the CEO

February 2014 - May 2017

- Assisted the president, CEO and senior management with administrative support

- Consistent management reporting, management and archival of confidential strategic files

- Critically analyzed project data and presented findings before management

- Dispensed superior customer service, and problem negotiation and resolution

- Prepared marketing reports/invoices to vendors and suppliers for marketing campaigns

- Established impeccable office administrative protocols compliant with budgetary requirements

- Coordinated front office staff to ensure proper phone coverage

- Created slogan for employees to inspire integrity and teamwork

- Organized employee events to encourage a team-player attitude and motivation

Tek Title, LLC

Escrow Officer Assistant/Receptionist

Chicago, IL

- Responsible for getting and ordering information for closings of tax certificates, dues, payoffs, surveys and many other documents

- Prepared files for closings

- Responsible for preparing, inputting and reviewing HUD disbursement worksheets and settlement statements

- Received various funding for closing

- Worked with clients, agents, sellers and buyers to facilitate closing process

EDUCATION

Northeastern Illinois University

B.A. English

Chicago, IL

June 2011

\section{SKILLS}

- Detail oriented and capable of multi-tasking

- Excellent at proofreading, data management, and record keeping

- Proficient with Microsoft Office Suite and social media, 65 wpm

- Proven capability to multi-task, prioritize, and adapt as business needs evolve 
Donna Ramsey

5525 W $24 \mathrm{Pl}$

Cicero, IL 60804

(708) 657-6210

ramseydonna8@gmail.com

$3 / 1 / 2017$

Dear Sir or Madam:

I am writing in response to your request for an Office Assistant / Business Administrator. The qualities, education and experience I possess are perfectly suited for the position described, and I am sure I would make an excellent candidate for the job.

For the past 4 years, I have worked in the Administrative field where my responsibilities included: office management and inventory duties; heavy data entry and formatting; regular correspondence tasks for my employers; and effective in-person interaction with clients, fellow employees and employers alike. I have managed intensive multi-line telephone systems and have become familiar with a variety of computer programs. The time I spent in administration has given me the skills I need to be an efficient, detail oriented, interpersonally-skilled assistant, and I am looking forward to applying these skills to this new job opportunity.

In addition to over a decade of pertinent experience, my Bachelors degree in English gives me an edge as it has trained me to be an excellent communicator with great writing skills. As an Administrative Assistant, these skills allow me to engage comfortably and articulately with clients even in high-stress situations and to handle any writing or editing assignment given to me with ease.

Please see my attached resume for further details about my past experience, and feel free to contact me, by phone or email, with any questions at all. I would also be happy to provide references from any former supervisors. I look forward to hearing from you soon and to meeting in person for an interview.

Respectfully yours,

Donna Ramsey 


\section{Donna Ramsey}

5525 W 24 PI Cicero, IL 60804

ramseydonna8@gmail.com

(708) 657-6210

Jan $2015-$ Jul 2017

Highland Solutions, Chicago, IL

Temporary Pool - Administrative Assistant

- Executive support - (SVPs, CMOs, directors, VPs, department heads, managers)

- All aspects of executive administrative/administrative assistant functions

- Heavy calendar management

- Prepared online service requests for departments, disbursements for payments, mileage forms

- Coordinated catering with internal and external vendors

- Worked with record storage for destruction of records

Aug 2013 - Dec 2014

The Salem Group, Oakbrook Terrace, IL

Executive Assistant

- Executive support - C-Level, executive, senior, mid-level and department heads

- Managed calendars using Outlook

- Handled all aspects of executive/administrative functions (i.e. international and domestic travel, scheduled, complex video conferencing meetings and calls)

- Streamlined and maintained databases for specific areas

- Created, researched and resolved any travel and expense discrepancies

- Assisted with real estate closing documents

- Verified and compiled doctor's school records, GPAs and medical exam scores

- Verified malpractice insurance information

- Followed-up on rotation schedules

- Directed administrative and support services

- Prepared operational budgets

- Directed facility maintenance and repair activities

- Coordinated employee training programs

- Purchased materials and equipment

Education

Northern Illinois University, DeKalb, IL

Bachelor of Arts, English, 2012

Skills

- Adept with Microsoft Word, Excel, PowerPoint, Outlook, and QuickBooks

- Exceptional communication and organizational skills, and business ethics

- Accounts payable and accounts receivable

- Ability to be self-directed and efficient in a fast-paced environment 